\title{
KONTRIBUSI HUTAN MILIK TERHADAP KESEJAHTERAAN PETANI DI DESA SUKOHARJO I KECAMATAN SUKOHARJO KABUPATEN PRINGSEWU
}

\section{(THE CONTRIBUTION OF PRIVATE FOREST FOR FARMERS WELFARE IN SUKOHARJO I VILLAGE SUKOHARJO DISTRICT PRINGSEWU REGENCY)}

\author{
Oleh : \\ Arantha Sabilla, Asihing Kustanti, dan Rudi Hilmanto \\ Jurusan Kehutanan Fakultas Pertanian Universitas Lampung \\ Jl. Sumatri Brojonegoro No 1 Bandarlampung. 35145 \\ E-mail: cst_antjasrocketmail@yahoo.co.id
}

\begin{abstract}
ABSTRAK
Hutan milik adalah hutan yang kepemilikan lahannya oleh rakyat dengan luas minimal 0,25 ha. Di Provinsi Lampung umumnya pola tanam yang diterapkan pada hutan milik adalah agroforestri. Agroforestri merupakan salah satu bentuk budidaya lahan secara multitajuk yang terdiri dari campuran pepohonan, semak, dengan atau tanaman pertanian disertai dengan ternak dalam satu bidang lahan. Sistem agroforestri memberikan manfaat ekonomis dan ekologis yang penting untuk petani, salah satunya adalah dapat meningkatkan pendapatan yang menunjang kesejahteraannya. Khususnya di desa ini kontribusi hutan milik pada kesejahteraan petani belum diketahui. Penelitian ini bertujuan untuk: (1) Mengetahui besarnya kontribusi hutan milik terhadap pendapatan petani di Desa Sukoharjo 1 Kecamatan Sukoharjo Kabupaten Pringsewu; (2) Mengetahui tingkat kemiskinan di Desa Sukoharjo 1 Kecamatan Sukoharjo Kabupaten Pringsewu dalam mengelola hutan milik; dan (3) Mengetahui tingkat kesejahteraan di Desa Sukoharjo 1 Kecamatan Sukoharjo Kabupaten Pringsewu dalam mengelola hutan milik.

Metode pengumpulan contoh (sample) menggunakan simple random sampling. Contoh diambil secara acak. Responden petani terpilih dalam penelitian ini sebanyak 41 kepala keluarga. Hasil penelitian menunjukkan bahwa: 1) Kontribusi hutan milik terhadap pendapatan adalah $83,27 \%$ atau sebesar Rp $62.591 .537,00 / \mathrm{kk} / \mathrm{ha} / \mathrm{tah}$ un dan non hutan milik 12.573.171 (16,73\%); 2) Tingkat kemiskinan rumah tangga responden 7,32\% termasuk dalam kategori paling miskin, 2,44\% termasuk dalam kategori rumah tangga miskin sekali, 2,44\% termasuk dalam kategori rumah tangga miskin, dan $87,80 \%$ responden termasuk ke dalam kategori di atas garis kemiskinan; 3) Tingkat kesejahteraan rumah tangga responden 12,20\% termasuk dalam kategori pra sejahtera, $19,51 \%$ termasuk dalam kategori sejahtera tahap I, $14,63 \%$ termasuk dalam kategori sejahtera tahap II, 46,34\% termasuk dalam kategori sejahtera tahap III, dan 7,32\% termasuk dalam kategori sejahtera tahap III Plus.
\end{abstract}

Kata kunci: agroforestri, kontribusi pendapatan, tingkat kemiskinan, tingkat kesejahteraan.

\begin{abstract}
Private forest was forest that land ownership by the people with a minimum area of 0.25 ha. In Lampung province generally cropping patterns were applied to private forests is agroforestry. Agroforestry was one of land use form in multicrown. It was consisting of a mixture of the trees, shrubs with an annual or plants often accompanied by cattle in one area. Agroforestry system contributed on ecological and economical to generate in farmers income. Especially in this village private forest contribution to the welfare of farmers were not yet known. This study aimed to: (1) Know how much the contribution of private forests
\end{abstract}


for income of farmers in Sukoharjo I Village Sukoharjo District Pringsewu Regency; (2) Know the poverty level of farmers from agroforestry; and (3) Know the welfare level of farmers from agroforestry. This research was conducted in the Sukoharjo 1 Village, Sukoharjo District Pringsewu Regency.

The samples of this research used simple random sampling. Selected respondents were 41 heads of families. The results showed that: 1) The contribution of private forest againts revenue was $83.27 \%$ or $R p$ 62,591,537.00 / kk / ha / year and non private forest was $12,573,171(16.73 \%)$; 2) The level of poverty of family was rate of $7.32 \%$ included in the category of the poorest, $2.44 \%$ belong to the category of poor households, $2.44 \%$ belong to the category of poor households, and $87.80 \%$ of the respondents belong to the category above the poverty line; and 3) The level of welfare of family was 12,20\% of respondents, it included in the category of pre-prosperous: $19.51 \%$ included in the category of prosperous phase I, 14.63\% included in the category of prosperous phase II, 46.34\% included in the category of prosperous phase III, and $7.32 \%$ included in the category of prosperous phase III Plus.

Keywords: agroforestry, the contribution of income, level of poverty, level of welfare.

\section{PENDAHULUAN}

\section{Latar Belakang}

Hutan milik sudah berkembang sejak tahun 1950-an di kalangan masyarakat dan dilakukan secara tradisional di lahan milik. Sistem budidaya pada hutan milik dilakukan dengan mengkombinasikan tanaman pertanian maupun dengan pola tanaman campuran pepohonan/ kayuan melalui sistem agroforestry. Bentuk budidaya hutan milik ini dapat berupa pekarangan, talun, maupun kebun campuran. Khusus di Pulau Sumatera dengan bertambahnya jumlah penduduk pemenuhan kebutuhan dari sumberdaya hutan semakin meningkat. Peningkatan ini terjadi akibat semakin tingginya permintaan terhadap komoditas agroforestri berupa: kayu bakar, bahan baku industri, dan jasa lingkungan hidup. Pengelolaan sumberdaya hutan tidak hanya ditujukan bagi pemenuhan kebutuhan akan kayu saja, tetapi masih banyak manfaat lain dari hutan yang tetap harus dijaga. Berbagai upaya terus dilakukan pemerintah maupun masyarakat untuk menjaga keberadaan hutan, salah satunya adalah mengembangkan hutan rakyat (Purnama, 2009).

Masyarakat Desa Sukoharjo I rata-rata bermata pencaharian sebagai petani. Perkiraan luas lahan yang dimiliki petani di Sukoharjo mencapai 200 ha, namun banyak lahan hutan tersebut telah dialihfungsikan oleh petani untuk membangun rumah permanen maupun semi permanen. Rumah tangga petani hutan milik mencapai 39\% atau sebanyak 446 rumah tangga (RT) dan petani non-hutan milik sebesar 61\% atau sebanyak 691 rumah tangga (RT) (Profil Pekon, 2015). Desa Sukoharjo 1 merupakan desa yang cukup terkenal dengan agroforestri wisata. Tenaga kerja di hutan milik di Desa Sukoharjo I memperoleh penghasilan yang cukup untuk kebutuhan hidup dan meningkatkan kesejahteraan. Aktivitas petani hutan milik sebagian besar melakukan usaha tani sampingan. Pengelolahan hutan milik tersebut menyebabkan pendapatan petani yang dihasilkan oleh hutan milik belum cukup dan belum maksimal. Sehingga pengolahan hutan milik perlu pengkajian tentang klasifikasi tingkat kemiskinan dan kesejahteraan terhadap petani yang memiliki hutan milik.

Kesejahteraan merupakan suatu hal yang bersifat subjektif, sehingga setiap keluarga atau individu didalamnya yang memiliki pedoman, tujuan, dan cara hidup yang berbeda akan memberikan nilai yang berbeda tentang faktor-faktor yang menentukan tingkat kesejahteraan (BKKBN,2014). Artinya ada segolongan orang menekankan kepada pengumpulan kekayaan 
dan memperoleh pendapatan yang tinggi sebagai unsur penting untuk mencapai kesejahteraan dalam kehidupan mereka. Tetapi segolongan orang lainnya memilih kehidupan keagamaan sebagai tingkat kesejahteraan yang lebih tinggi dalam mencapai kepuasan hidup. Begitu juga segolongan orang lainnya memilih memperoleh masa lapang (leisure). Desa Sukoharjo 1 ada beberapa keluarga yang belum terpenuhi tingkat kesejahteraanya. Padahal prospek hasil hutan milik dapat dijadikan patokan dari tingkat kesejahteraan kehidupan petani. Hutan milik di Desa Sukoharjo 1 belum diketahui seberapa besar kontribusinya terhadap pendapatan petani. Data tersebut digunakan sebagai bahan pertimbangan serta pengembangan hutan milik di Desa Sukoharjo I, sehingga dapat meningkatkan kontribusi yang besar bagi pendapatan petani hutan milik secara berkelanjutan dan juga dapat melestarikan hutan miliknya sendiri.

\section{Tujuan Penelitian}

1. Mengetahui besarnya kontribusi hutan milik terhadap pendapatan petani di Desa Sukoharjo I Kecamatan Sukoharjo Kabupaten Pringsewu.

2. Mengetahui proporsi kemiskinan di Desa Sukoharjo 1 Kecamatan Sukoharjo Kabupaten Pringsewu dalam mengelola hutan rakyat.

3. Mengetahui tingkat kesejahteraan di Desa Sukoharjo 1 Kecamatan Sukoharjo Kabupaten Pringsewu dalam mengelola hutan milik.

\section{METODE PENELITIAN}

\section{Waktu dan Tempat}

Penelitian ini dilaksanakan di Desa Sukoharjo 1 Kecamatan Sukoharjo Kabupaten Pringsewu. Waktu penelitian yaitu pada Bulan Januari sampai dengan Bulan Februari 2015.

\section{Alat dan Bahan}

Alat yang digunakan dalam penelitian ini yaitu alat tulis, kamera, kuesioner, dan komputer. Objek penelitian ini yaitu petani yang mengelola hutan milik di Desa Sukoharjo 1.

\section{Jenis Data}

Data yang digunakan dalam penelitian ini adalah data primer dan data sekunder. Data primer didapat dari wawancara langsung dengan responden. Data responden yang dikumpulkan adalah mengenai karakteristik responden, data pendapatan petani dari hasil pengelolaan hutan milik dan non hutan milik, tingkat ekonomi petani hutan milik seperti tingkat kemiskinan rumah tangga petani dan tingkat kesejahteraan rumah tangga petani serta pengeluaran rumah tangga. Data sekunder meliputi keadaan umum lokasi penelitian baik lingkungan fisik, sosial ekonomi masyarakat, data-data statistik identitas penduduk, dan buku-buku literatur lain terkait kesejahteraan petani serta data-data lain yang berkaitan dengan penelitian yang bersumber dari pustaka ataupun instansi terkait.

\section{Cara pengumpulan data}

Pengumpulan data dilakukan dengan wawancara dan studi pustaka. Wawancara dilakukan sebagai upaya untuk memperoleh data primer. Studi pustaka merupakan metode pengumpulan data sekunder dengan cara membaca dan mengutip teori-teori yang berasal dari buku dan tulisan-tulisan lain yang relevan dengan penelitian.

\section{Metode pengambilan sampel}

Populasi dalam penelitian ini adalah petani pengusaha hutan milik dengan sistem agroforestri di Desa Sukoharjo 1 Kabupaten Pringsewu sebanyak 446 responden. Menurut Arikunto (2006) jika populasi lebih dari 100 maka batas error yang digunakan adalah 10 - 
15\%. Penentuan besar sampel menggunakan rumus Slovin (Soewadji, 2012). Batas eror yang digunakan dalam pengambilan sampel ini adalah $15 \%$ karena akan menunjang data, maka jumlah sampel petani agroforestri adalah sebanyak 41 responden. Pemilihan sampel dilakukan secara purposive sampling yaitu pengambilan sample berdasarkan kesengajaan (Soekartawi, 1995) dengan pertimbangan responden adalah petani yang mengelola hutan milik dengan sistem agroforestri.

\section{Metode Pengolahan dan Analisis Data}

\section{Kontribusi terhadap pendapatan total rumah tangga}

Menurut Soekartawi (1995) pendapatan adalah selisih antara penerimaan dengan semua biaya. Sedangkan penerimaan petani adalah perkalian antara produksi yang diperoleh dengan harga jual.

$$
\begin{array}{ll}
\mathrm{Pd}=\mathrm{TR}-\mathrm{TC} & \mathrm{Pd}=\text { Total Pendapatan } \\
\mathrm{TR}=\text { Total penerimaan } & \mathrm{TC}=\text { Total Biaya }
\end{array}
$$

Kontribusi terhadap pendapatan total petani

$$
\begin{aligned}
& \overline{K r}=\frac{\bar{R}}{\overline{p t}} \times 100 \% \\
& \overline{K r}=\text { Kontribusi dari hutan milik } \\
& \bar{R}=\text { Pendapatan petani dari sistem Agroforestri (Kebun, pertanian, peternakan, } \\
& \quad \text { perikanan) } \\
& \overline{P t}=\text { Pendapatan total rumah tangga petani. }
\end{aligned}
$$

\section{Klasifikasi tingkat kesejahteraan dan tingkat kemiskinan petani}

Pada tahap pengumpulan data, data analisa telah terkumpul dengan lengkap sesuai kebutuhan. Tujuan pengolahan data adalah untuk menyederhanakan seluruh data yang terkumpul dan menyajikan dalam susunan yang baik dan rapi. Teknik analisis data yang digunakan dalam penelitian ini adalah analisis deskriptif kuantitatif untuk menjelaskan karakteristik ekonomi petani dan kesejahteraan petani hutan milik di Desa Sukoharjo. Analisa data dalam penelitian ini menggunakan tabel frekuensi. Tabel frekuensi digunakan untuk mengetahui pendapatan petani dan tingkat ekonomi petani, dalam penelitian ini tingkat ekonomi ditentukan berdasarkan kriteria Sajogyo (1996) untuk kemiskinan. Kriteria indikator Sajogyo (1996) adalah sebagai berikut: kelompok miskin, kelompok miskin sekali, kelompok paling miskin. Analisis data untuk tingkat kesejahteraan adalah indikator keluarga sejahtera menurut BKKBN. Indikator ini relatif cocok karena mengukur secara langsung tingkat kesejahteraan keluarga. Kriteria indikator BKKBN adalah sebagai berikut: pra sejahtera, sejahtera I, sejahtera II, sejahtera III, sejahtera III plus.

\section{HASIL DAN PEMBAHASAN}

\section{Kontribusi Hutan Milik terhadap Pendapatan Petani}

Pendapatan dalam penelitian ini adalah total pendapatan petani yang telah dikurangi dengan biaya produksi dalam usaha hutan milik. Pendapatan hutan milik merupakan penjumlahan pendapatan dari kebun, perikanan, peternakan dan pertanian. Pendapatan non hutan milik adalah total penjumlahan pendapatan dari berdagang, Pegawai Negeri Sipil (PNS), buruh, pengrajin dan jasa. Data pendapatan responden petani hutan milik disajikan pada Tabel 1. 
Berdasarkan Tabel 1, Kontribusi hutan milik tehadap pendapatan petani adalah $83,27 \%$ atau rata-rata sebesar $\mathrm{Rp} 62.591 .537,00 / \mathrm{kk} / \mathrm{ha} /$ tahun. Kontribusi non hutan milik adalah $16,73 \%$ atau rata-rata sebesar Rp 12.573.171,00/kk/tahun. Pendapatan petani hutan milik memberikan kontribusi yang lebih besar dibandingkan dengan kontribusi non hutan milik dikarenakan petani di Desa Sukoharjo I memiliki hutan milik yang kompleks dimana pendapatan hutan milik berasal dari kebun, pertanian, peternakan dan perikanan.

Tabel 1. Kontribusi Pendapatan Seluruh Responden Petani Hutan Milik ha/tahun

\begin{tabular}{lccc}
\hline $\begin{array}{c}\text { Sumber } \\
\text { Pendapatan }\end{array}$ & $\begin{array}{c}\text { Pendapatan } \\
(\mathbf{R p} / \mathbf{t h})\end{array}$ & $\begin{array}{c}\text { Rata-rata } \\
\text { Pendapatan (Rp/th) }\end{array}$ & $\begin{array}{c}\text { Kontribusi } \\
\text { (\%) }\end{array}$ \\
\hline Hutan Milik & 2.566 .253 .000 & 62.591 .537 & 83,27 \\
- Kebun & 1.471 .881 .000 & 35.899 .537 & 47,76 \\
- Pertanian (Padi) & 373.772 .000 & 9.116 .390 & 12,13 \\
- Peternakan & 536.400 .000 & 13.082 .927 & 17,41 \\
- Perikanan & 184.200 .000 & 4.492 .683 & 5,98 \\
& & & \\
Non Hutan Milik & 515.500 .000 & 12.573 .171 & 16,73 \\
- PNS & 196.800 .000 & 4.800 .000 & 6,39 \\
- Buruh & 117.300 .000 & 2.860 .976 & 3,81 \\
- Pengrajin & 14.400 .000 & 351.220 & 0,47 \\
- Dagang & 90.000 .000 & 2.195 .122 & 2,92 \\
- Jasa & 97.000 .000 & 2.365 .854 & 3,15 \\
\hline Total & 3.081 .753 .000 & 75.164 .707 & 100 \\
\hline Sumber: Data & & & \\
\hline
\end{tabular}

Sumber: Data primer (2015)

\section{Pendapatan Petani Hutan Milik dari Kebun, Pertanian, Peternakan, Perikanan dan Non Hutan Milik}

Berdasarkan Tabel 1, Hutan milik memberikan kontribusi yang lebih besar $(83,27 \%)$ dibanding dengan pendapatan lainnya dikarenakan mayoritas responden bergantung dengan lahan hutan milik untuk memenuhi kebutuhan rumah tangganya. Pendapatan dari hutan milik lebih besar karena kebun memberikan kontribusi yang cukup besar yaitu 47,76\% atau sebesar 35.899.537,00/kk/ha/tahun. Lahan kebun menggabungkan perkebunan dengan tanaman kehutanan atau tanaman berkayu dan tanaman pertanian seperti kakao (Theobroma cacao), kopi (Coffea arabica), pisang (Musa paradisiaca), kelapa (Cocos nucifera), sawit (Elaeis guineensis) tergolong tanaman perkebunan. Tanaman kehutanan yaitu karet (Hevea brasiliensis), sengon (Enterolobium cylocarpum), petai (Parkia speciosa), bayur (Pterospermum javanicum). Tanaman seperti jagung (Zea mays), terong (Solanum melongena), kangkung (Ipomea aquatica), cabe (Capsicum annum) dan kacang tanah (Arachis hypogea) merupakan tanaman pertanian. Kakao merupakan tanaman yang paling banyak dibudidayakan petani sehingga kakao memberikan kontribusi yang paling besar terhadap pendapatan petani yaitu $43.05 \%$ atau $\mathrm{Rp} 19.381 .488,00 / \mathrm{kk} / \mathrm{ha} / \mathrm{tahun}$ seperti yang tertera pada Tabel 2 .

Tabel 2. Pendapatan Jenis Tanaman Hutan Milik/Ha/tahun.

\begin{tabular}{lccc}
\hline \multicolumn{1}{c}{ Jenis Tanaman } & $\begin{array}{c}\text { Pendapatan/ha/tahun } \\
\text { (Rupiah) }\end{array}$ & $\begin{array}{c}\text { Rata-rata/kk/ha/tahun } \\
\text { (Rupiah) }\end{array}$ & $\begin{array}{c}\text { Persentase } \\
(\%)\end{array}$ \\
\hline Kakao & 794.641 .000 & 19.381 .488 & 43,05 \\
Kopi & 8.700 .000 & 212.195 & 0,47 \\
Pisang & 1.200 .000 & 29.268 & 0,07 \\
Jagung/kangkung & 6.728 .000 & 164.098 & 0,36 \\
Sawit & 86.095 .000 & 2.099 .878 & 4,66 \\
Karet & 124.127 .000 & 3.027 .488 & 6,73 \\
Sengon & 250.000 .000 & 6.097 .561 & 13,55 \\
\hline
\end{tabular}




\begin{tabular}{lrrr}
\hline Pete & 800.000 & 19.512 & 0,04 \\
Kelapa & 30.840 .000 & 752.195 & 1,67 \\
Bayur & 168.750 .000 & 4.115 .854 & 9,14 \\
Padi & 264.140 .000 & 6.442 .439 & 14,31 \\
Terong & 93.936 .000 & 2.291 .112 & 5,09 \\
Cabe/kacang & 15.696 .000 & 382.829 & 0,85 \\
\hline Jumlah & 1.845 .653 .000 & 45.015 .927 & 100 \\
\hline
\end{tabular}

Sumber: Data primer (2015)

Tanaman kopi memberikan kontribusi $0,47 \%$ (Tabel 2), karena banyak petani yang mengganti tanaman kopi dengan tanaman lain seperti kakao dan karet. Petani mengganti tanaman kopi karena produktivitas kopi semakin menurun, Sedangkan karet memberikan kontribusi $6,73 \%$ dikarenakan sebagian besar karet yang ditanam sudah dapat dilakukan pemanenan telah berumur 5-10 tahun. Kelapa memberikan kontribusi 1,67\% lebih kecil dari kontribusi karet dan salah satu komoditi yang memberikan banyak kontribusi setelah kakao karena jumlah tanaman kelapa yang cukup banyak dan produktivitas yang tinggi.

Tanaman kehutanan yang dimiliki petani walaupun dijadikan naungan atau tanaman pagar, tetap memberikan kontribusi bagi petani. Tanaman kehutanan yang ditanam seperti mahoni, akasia, waru, medang, albazia, gaharu, sengon, jati, bayur dan cempaka. Tanaman Kehutanan tersebut ada yang dijual dan ada juga yang ditebang untuk membangun rumah, membangun kandang ternak dan kebutuhan lainnya. Berdasarkan hasil penelitian Sanudin dan Priambodo (2013) penerapan sistem agroforestri diperoleh kontinyuitas pendapatan dimana tanaman semusim dan perkebunan digunakan untuk memenuhi kebutuhan sehari-hari. Sedangkan pendapatan dari kayu selain bisa digunakan untuk kebutuhan sehari-hari juga untuk memenuhi kebutuhan yang sifatnya temporal seperti kebutuhan anak sekolah, hajatan, membangun rumah dan kebutuhan mendesak lainnya. Pendapatan dari pertanian memberikan kontribusi terhadap pendapatan petani yaitu 12,13\% atau sebesar Rp 9.116.390,00/ $\mathrm{kk} / \mathrm{ha} /$ tahun. Berdasarkan hasil wawancara responden penelitian memiliki lahan persawahan dari 0,25-2 hektar yang memberikan pendapatan 1-2,5 ton beras setiap panen dengan harga jual beras Rp 10.000,00/kg.

Pendapatan dari peternakan memberikan kontribusi terhadap pendapatan petani 17,41\% atau sebesar Rp 13.082.927,00/kk/tahun. Ternak yang dimiliki petani adalah ayam ras, sapi dan kambing. Tidak semua ternak dijual oleh responden sehingga kontribusi ternak terhadap pendapatan total petani tidak terlalu besar. Pendapatan dari perikanan memberikan kontribusi terhadap pendapatan petani 5,98\% atau sebanyak $\mathrm{Rp} 4.492 .683,00 /$ tahun. Responden membudidayakan ikan lele, gurame dan mas. Luas kolam yang dimiliki petani dari $800 \mathrm{~m}^{2}-2300 \mathrm{~m}^{2}$ dengan sistem pengairan berasal dari cekdam atau bendungan.

Pendapatan non hutan milik berasal dari buruh, pengrajin, berdagang, PNS (Pegawai Negeri Sipil), dan jasa. Pendapatan dari buruh memberikan kontribusi 3,81\% sebesar Rp. $2.860 .976,00 /$ tahun. Usaha buruh yang dilakukan yaitu usaha stek tanaman coklat, panggul barang dan pabrik. Pendapatan dari usaha berdagang memberikan kontribusi 2,92\% atau Rp. $2.195 .122,00 / \mathrm{kk} /$ tahun. Usaha berdagang yang dilakukan adalah membuka toko sembako dirumah. Pendapatan dari PNS (Pegawai Negeri Sipil) seperti guru memberikan kontribusi $6,39 \%$ atau sebanyak Rp 4.800.000,00/kk/tahun. Pendapatan dari jasa memberikan kontribusi $3,15 \%$ atau sebanyak $\mathrm{Rp} 2.365 .854,00 / \mathrm{kk} / \mathrm{tahun}$ dan pendapatan dari pengrajin memberikan kontribusi $0,47 \%$ atau sebanyak $\mathrm{Rp} 351.220,00 / \mathrm{kk} /$ tahun.

\section{Tingkat Kemiskinan Rumah Tangga Petani Hutan Milik}

Penentuan tingkat kemiskinan rumah tangga petani hutan milik dalam penelitian ini menggunakan kriteria tingkat kemiskinan menurut Sajogyo (1996) yaitu di atas garis kemiskinan, miskin, miskin sekali, dan paling miskin. Penentuan tingkat kemiskinan dalam 
penelitian ini menggunakan pendapatan per kapita responden dalam satu tahun. Pendapatan per kapita diperoleh dari hasil pembagian total pendapatan responden dalam satu tahun dibagi dengan jumlah tanggungan keluarga responden.

Tabel 3. Proporsi Kemiskinan

\begin{tabular}{clcc}
\hline Pendapatan perkapita $(\mathrm{Rp})$ & Kategori & Frekuensi & $\%$ \\
\hline $1.800 .000,00$ & Paling miskin & 3 & 7,32 \\
$1.801 .000,00-2.400 .000,00$ & Miskin Sekali & 1 & 2,44 \\
$2.401 .000,00-3.200 .000,00$ & Miskin & 1 & 2,44 \\
$3.200 .000,00$ & $\begin{array}{c}\text { Di Atas Garis } \\
\text { Kemiskinan }\end{array}$ & 36 & 87,80 \\
\hline Jumlah & & 41 & 100 \\
\hline
\end{tabular}

Sumber: Data primer (2015)

Berdasarkan tabel di atas dapat diketahui bahwa sebanyak $87,80 \%$ dari jumlah responden termasuk dalam kategori di atas garis kemiskinan dikatakan sejahtera karena memiliki pendapatan per kapita 3.200.000,00 per tahun. Pendapatan per kapita tersebut berasal dari pendapatan hutan milik, pertanian, peternakan, perikanan dan non hutan milik. Kebutuhan rumah tangga pun bisa tercukupi. Menurut Nursanti (1999) banyaknya jumlah responden yang termasuk dalam klasifikasi di atas garis kemiskinan, dikarenakan adanya tambahan pendapatan dari usaha hutan rakyat lain dan usaha non hutan rakyat. Kehidupan keluarga responden di atas garis kemiskinan tercapai tidak hanya dari satu sektor usaha saja dalam hutan rakyat tetapi ditambah dengan beberapa sektor usaha yang lainnya. Sebanyak $7,32 \%$ dari jumlah responden termasuk kategori paling miskin dengan pendapatan per kapita $1.800 .000,00$ per tahun.

Responden bisa masuk kedalam kategori paling miskin dikarenakan pendapatan kecil yaitu hanya berasal dari sektor pertanian saja misalnya hanya bertani padi. Data persentase penduduk miskin menurut provinsi, kabupaten, kota dan sektor bekerja pada tahun 2004 (BPS, 2004) menunjukkan persentase terbesar penduduk miskin hampir di seluruh kabupaten atau provinsi adalah bekerja di sektor pertanian. Tanggungan rumah tangga responden cukup besar. Kebutuhan responden semakin banyak sedangkan pendapatan tidak bertambah, hal ini menyebabkan kemiskinan di daerah responden.

Proporsi Kesejahteraan Rumah Tangga Petani Hutan Milik

Pada penelitian ini yang digunakan untuk menentukan tingkat kesejahteraan rumah tangga petani hutan milik di Desa Sukoharjo I adalah berdasarkan parameter atau asumsi dari BKKBN. Petani hutan milik di Desa Sukoharjo I dapat dilihat melalui pengelompokan tingkat kesejahteraannya.

Tabel 4. Proporsi Kesejahteraan di Desa Sukoharjo I Kecamatan Sukoharjo Kabupaten Pringsewu

\begin{tabular}{lcc}
\hline \multicolumn{1}{c}{ Tingkat Kesejahteraan } & Frekuensi & Proporsi (\%) \\
\hline Pra Sejahtera & 5 & 12,20 \\
Kesejahteraan Tahap I & 8 & 19,51 \\
Kesejahteraan Tahap II & 6 & 14,63 \\
Kesejahteraan Tahap III & 19 & 46,34 \\
Kesejahteraan Tahap III Plus & 3 & 7,32 \\
\hline Jumlah & 41 & 100 \\
\hline
\end{tabular}

Sumber: Data primer (2015)

Berdasarkan tabel di atas dapat diketahui bahwa sebanyak 19 responden atau 46,34\% dari jumlah responden termasuk ke dalam kategori kesejahteraan tahap III dan rumah tangga responden yang masuk dalam kategori kesejahteraan tahap III plus ada 7,32\%. Responden 
bisa masuk dalam kategori kesejahteraan tahap III karena kebutuhan dasar minimum, kebutuhan sosial psikologis dan kebutuhan pengembangnya bisa tercukupi. Hal ini menunjukkan bahwa kesejahteraan petani hutan milik sudah baik meskipun sebagian besar petani hutan milik masih dalam kategori kesejahteraan tahap III. Para responden bekerja menjadi petani hutan milik berharap supaya kebutuhannya bisa tercukupi dan kesejahteraan rumah tangganya bisa meningkat. Menurut Febrianto (2011) hal ini dapat dilihat dari indikator-indikator pemenuhan kebutuhan yang dipenuhi oleh rumah tangga responden sesuai dengan kriteria BKKBN. Semakin banyak indikator pemenuhan kebutuhan yang dapat dipenuhi maka semakin tinggi tingkat kesejahteraan, dan sebaliknya, semakin sedikit indikator pemenuhan kebutuhan yang dapat dipenuhi maka semakin rendah tingkat kesejahteraan.

\section{Keterkaitan Tingkat Kemiskinan dan Tingkat Kesejahteraan Petani}

Penduduk miskin adalah penduduk yang memiliki rata-rata pengeluaran per kapita per bulan dibawah garis kemiskinan (Laka, 2014). Kesejahteraan dapat diartikan sebagai tingkat kemampuan seseorang dalam memenuhi kebutuhan primernya (basic needs) (Ahmad, 2015). Dari dua pendapat di atas artinya kemiskinan dan kesejahteraan mempunyai keterkaitan ibarat dua sisi mata uang yang tidak terlepas dimanapun diletakkan. Keterkaitan antara kemiskinan dengan kesejahteraan dilihat dari hasil analisis data perkapita dan analisis data kesejahteraan tampak jelas keterkaitannya antara responden yang tergolong dibawah garis kemiskinan dengan responden yang tergolong prasejahtera. Responden tergolong dibawah garis kemiskinan sebanyak 5 responden atau $12,20 \%$ dan responden yang tergolong prasejahtera sebanyak 5 responden, atas nama responden tersebut adalah sama.

Tabel 5. Keterkaitan Tingkat Kemiskinan dan Tingkat Kesejahteraan

\begin{tabular}{clclc}
\hline No & Tingkat Kemiskinan & Frekuensi & Tingkat Kesejahteraan & Frekuensi \\
\hline 1 & Paling miskin & 3 & Prasejahtera & 5 \\
2 & Miskin sekali & 1 & Sejahtera Tahap I & 8 \\
3 & Miskin & 1 & Sejahtera Tahap II & 6 \\
4 & Di atas garis kemiskinan & 36 & Sejahtera Tahap III dan & 22 \\
\hline \multicolumn{2}{c}{ Jumlah } & 41 & & 41 \\
\hline
\end{tabular}

Sumber: Data primer 2015

Keterkaitan dari 41 responden sangat berkaitan kategori tingkat kemiskinan dengan kategori tingkat kesejahteraanya. Keterkaitan tersebut dapat dilihat dari jumlah 41 responden yang tergolong kategori di atas garis kemiskinan sebanyak 36 responden atau $87.80 \%$ dengan tingkat kesejahteraan petani tergolong kategori sejahtera tahap I, II, III dan III plus sebanyak 36 responden atau 87,80\%. Kategori tingkat kemiskinan dibawah garis kemiskinan dari 41 responden terdapat 5 responden kategori paling miskin, miskin sekali, dan miskin atau $12,20 \%$ sama dengan kategori tingkat prasejahtera sebanyak 5 responden dari jumlah keseluruhan 41 responden atau 12,20\%. Jadi tingkat kesejahteraan petani di Desa Sukoharjo I dari kesejahteraan tahap I, kesejahteraan tahap II, kesejahteraan tahap III, kesejahteraan Tahap III plus termasuk kategori keluarga petani di atas garis kemiskinan. 


\section{SIMPULAN DAN SARAN}

\section{Simpulan}

Berdasarkan hasil penelitian maka dapat diambil beberapa kesimpulan yaitu:

1. Kontribusi hutan milik terhadap pendapatan petani adalah $83,27 \%$ atau sebesar $\mathrm{Rp}$ $62.591 .537,00 / \mathrm{kk} / \mathrm{ha} /$ tahun merupakan kontribusi tertinggi dibanding dengan pendapatan lainnya yaitu non hutan milik dikarenakan mayoritas responden bergantung dengan lahan hutan milik untuk memenuhi kebutuhan rumah tangganya.

2. Proporsi kemiskinan rumah tangga petani hutan milik di Desa Sukoharjo I sebagian besar yaitu $87,80 \%$ berada di atas garis kemiskinan atau ditinjau dari kesejahteraan tergolong sudah sejahtera dalam kehidupan sehari-hari. Responden yang masuk dalam kategori rumah tangga paling miskin sebanyak $7,32 \%$, sedangkan petani yang masuk dalam kategori rumah tangga miskin sekali dan miskin sebanyak 2,44\%.

3. Tingkat kesejahteraan rumah tangga petani hutan milik di Desa Sukoharjo I sebagian besar petani sudah masuk dalam kategori rumah tangga sejahtera tahap III yaitu sebanyak 46,34\% sedangkan petani yang masih tergolong dalam tahap pra sejahtera yaitu sebanyak $12,20 \%$, hanya ada $7,32 \%$ yang masuk dalam kategori rumah tangga sejahtera tahap III plus. Rumah tangga petani yang masuk dalam kategori sejahtera tahap I sebanyak $19,51 \%$ dan rumah tangga sejahtera tahap II sebanyak $14,63 \%$.

\section{Saran}

Pengembangan jenis kakao memberikan kontribusi yang paling besar bagi pendapatan petani, dengan demikian petani agroforestri di Desa Sukoharjo 1 agar lebih intensif lagi dalam pengembangan dan pengelolaan kakao seperti kegiatan yang dilakukan antara lain dengan metode pemberian pupuk, pemangkasan cabang dan pembasmian hama sehingga produktivitas kakao dapat dipertahankan dan ditingkatkan.

\section{DAFTAR PUSTAKA}

Ahmad, L. 2015. Kesejahteraan Kemiskinan dan Program KB di Jawa Barat Diakses pada tanggal 10 Mei 2016 Pukul 12.41 WIB. http://jabar.bkkbn.go.id/Lists/Artikel /DispForm.aspx?ID=588\&ContentTypeId=0x01003DCABABC04B7084595DA3644 23DE7897

Arikunto S. 2006. Prosedur Penelitian Suatu Pendekatan Praktek. Buku. PT Rineka Cipta. Jakarta. $370 \mathrm{p}$.

Badan Kependudukan Keluarga Berencana Nasional. 2014. Tata Cara Pelaksanaan Pencatatan dan Pelaporan Pendataan Keluarga Program Kependudukan, Keluarga Berencana dan Pembangunan Keluarga. Buku. Gerakan Keluarga Berencana Nasional. Jakarta. 162 p.

Badan Pusat Statistik. 2004. Data dan Informasi Kemiskinan Tahun 2004. Buku. Badan Pusat Statistik Jakarta. Jakarta. 155 p. 
Febrianto, K.R. 2011. Tingkat Kesejahteraan Rumah Tangga Petani Kacang Tanah di Desa Candirejo Kecamatan Borobudur Kabupaten Magelang Propinsi Jawa Tengah. Skripsi. Universitas Negeri Yogyakarta. Yogyakarta. 135 p.

Laka, M. 2014. Pengaruh Pertumbuhan Penduduk Terhadap Pembangunan Bidang Kemiskinan dan Kesejahteraan. Skripsi. Universitas Negeri Makassar. Makassar. 23 p.

Nursanti, F. 1999. Tingkat Pendapatan dan Kesejahteraan Rumah Tangga Petani Pembenih lkan Mas di Desa Paku Tandang dan Desa Cikoneng, Kecamatan Ciparay, Kabupaten Bandung, Propinsi Jawa Barat. Skripsi. Institut Pertanian Bogor. Bogor. $149 \mathrm{p}$.

Profil Pekon Sukoharjo I. 2015. Profile Pekon Sukoharjo I. Desa Sukoharjo I. Buku. Kabupaten Pringsewu. 9 p.

Purnama, I. 2009. Peran Hutan Rakyat dalam Perekonomian Masyarakat Desa di Desa Wangunjaya Kecamatan Cugenang Kabupaten Cianjur Propinsi Jawa Barat. Skripsi. Institut Pertanian Bogor. Bogor. 149 p.

Sajogyo. 1996. Garis Kemiskinan dan Kebutuhan Minimum Pangan. Buku. Aditya Media. Yogyakarta. $11 \mathrm{p}$.

Sanudin dan Priambodo, D. 2013. Analisis sistem dalam pengelolaan hutan rakyat agroforestry di Hulu DAS Citanduy kasus di Desa Sukamaju, Ciamis. Jurnal Online Pertanian Tropik. 1(1): 33-46.

Soekartawi. 1995. Analisis Usahatani. Buku. UI-Press. Jakarta. 57 p.

Soewadji, J. 2012. Pengantar Metodologi Penelitian. Buku. Mitra Wacana Media. Jakarta. $135 \mathrm{p}$. 